\title{
Role of the Sucrose Synthase Encoding PrSus1 Gene in the Development of the Parasitic Plant Phelipanche ramosa L. (Pomel)
}

\author{
Thomas Péron, ${ }^{1}$ Christophe Véronési, ${ }^{1}$ Eric Mortreau, ${ }^{2}$ Jean-Bernard Pouvreau, ${ }^{1}$ Séverine Thoiron, ${ }^{1}$ \\ Nathalie Leduc, ${ }^{3}$ Philippe Delavault, ${ }^{1}$ and Philippe Simier ${ }^{1}$ \\ ${ }^{1}$ LUNAM Université, Laboratoire de Biologie et Pathologie Végétales, IFR 149 QUASAV, UFR Sciences et Techniques, 44322 \\ Nantes, France; ${ }^{2}$ AGROCAMPUS-OUEST, UMR A 462 SAGAH, IFR 149 QUASAV, 2 rue André Le Nôtre, F-49045 Angers \\ Cedex, France; ' ${ }^{3}$ nniversité d'Angers, UFR Sciences, UMR A 462 SAGAH, IFR 149 QUASAV, 2 Bd Lavoisier, F-49045 Angers \\ Cedex, France
}

Submitted 3 October 2011. Accepted 9 November 2011.

\begin{abstract}
Phelipanche ramosa $\mathrm{L}$. (Pomel) is a major root-parasitic weed attacking many important crops. Success in controlling this parasite is rare and a better understanding of its unique biology is needed to develop new specific control strategies. In the present study, quantitative polymerase chain reaction experiments showed that sucrose synthase encoding PrSus1 transcripts accumulate at their highest level once the parasite is connected to the host (tomato) vascular system, mainly in the parasite tubercles, which bear numerous adventitious roots. In situ hybridization experiments revealed strong PrSus1 expression in both shoot and root apices, especially in shoot apical meristems and in the vascular tissues of scale leaves and stems, and in the apical meristems and developing xylem in roots. In addition, immunolocalization experiments showed that a sucrose synthase protein co-localized with cell-wall thickening in xylem elements. These findings highlight the role of PrSus 1 in the utilization of host-derived sucrose in meristematic areas and in cellulose biosynthesis in differentiating vascular elements. We also demonstrate that PrSus1 is downregulated in response to 2,3,5-triiodobenzoic acid-induced inhibition of polar auxin transport in the host stem, suggesting that PrSus1 activity in xylem maturation is controlled by hostderived auxin.
\end{abstract}

Broomrapes (Orobanche spp. and Phelipanche spp.) are achlorophyllous root-parasitic plants. Phelipanche ramosa L. Pomel (syn. Orobanche ramosa) is a harmful weedy parasitic plant in various agrosystems (Parker 2009) (illustrations can be found on the Parasitic Plant Connection website). P. ramosa takes advantages of ideal growth conditions in the Mediterranean Sea Basin and in Asia Minor, where it parasitizes a large range of host crops, primarily tomato and tobacco. Parasite development is divided into preparasitic and parasitic stages. The preparasitic stage starts with seed preconditioning followed by germination, which is induced by molecules secreted in the rhizosphere by the roots of host plants. Most of the known germination stimulants are strigolactones (Yoneyama et

Corresponding author: P. Simier; Telephone: +332 511256 16; Fax: +33 2511256 12; E-mail: philippe.simier@univ-nantes.fr

Nucleotide sequences: PrSus1 (JN048797), PrSus1 promoter (JN204913), PrEF1 $\alpha 1$ (HM219554), PrCCD7 (JN412814), and PrIPT (JN412815). al. 2009). Germination leads to the emergence of a radicle which attaches to the host root surface. The parasitic phase starts with the penetration of the parasite into the host root through a differentiating haustorium which connects to the host vascular tissues. The haustorium contains both xylem and phloem (Hibberd and Jeschke 2001) and serves as both an attaching organ and a bridge for water and nutrient transfer from the host. The attached parasite acts as a root (Bar-Nun and al. 2008), then diverts hormones and photoassimilates from the host plant, mainly auxin and sucrose (Abbes et al. 2009; Aber et al. 1983; Bar-Nun et al. 2008). The parasite first develops a tubercle carrying numerous adventitious roots; the apical bud of this tubercle give rise to a subterranean shoot and then to a branched flowering spike after emergence from the soil. Success in controlling broomrape is rare (Perez de Luque et al. 2009; Rispail et al. 2007) and there is an urgent need to better understand the physiological and metabolic features of this root-parasitic plant to develop new specific control strategies (Aly et al. 2009). The transfer of sucrose from the host and its rapid utilization by the achlorophyllous parasite corresponds to major functional processes of the host-parasite relationship. Sucrose is mainly used in $P$. ramosa for growth and accumulation of hexoses and, to a lesser extent, mannitol and starch (Delavault et al. 2002). In plants, both invertases (EC 3.2.1.26) and sucrose synthases (SUS) (EC 2.4.1.13) are involved in sucrose utilization (Sturm and Tang 1999). A recent study has shown that a dominant vacuolar invertase, PrSAI1, plays an active role in cell turgor and growth during the full life cycle of the parasite $P$. ramosa (Draie et al. 2011). Nevertheless, the involvement of SUS in parasite development needs to be clarified.

SUS are glycosyl transferases which convert sucrose into fructose and UDP-glucose in the presence of UDP (UDP-glucose: D-fructose 2-glucosyltransferase) and play multiple pivotal roles. SUS are commonly associated with glucan synthesis in starch deposition in plastids (Baroja-Fernández et al. 2009; Chourey and Taliercio 1994) and in the thickening of secondary cell walls in vascular tissues (Coleman et al. 2009; Salnikov et al. 2003). Their role in energy conservation is also assumed, notably under low oxygen conditions (Albrecht and Mustroph 2003; Ricard et al. 1998), maintaining cell growth in tissues naturally deprived in oxygen such as tubercles (Bologa et al. 2003), developing seed (Rolletschek et al. 2002), and phloem (van Dongen et al. 2003). Oxygen and related sugar deprivation can induce many SUS-encoding genes (Koch 1996; Koch 
et al. 1992; Winter and Huber 2000). In phloem, SUS may be involved in energy delivery for sucrose loading and in callose formation in response to wounding and pathogen infection (Koch 2004). Various locations of SUS have been reported: they can be bound to plasmalemma associated with cellulose synthase and callose synthase (Delmer and Amor 1995; Salnikov et al. 2001; Subbaiah and Sachs 2001), to the cell wall (Salnikov et al. 2003; Ruan 2007; Persia et al. 2008), or to membranes of several types of organelles, including Golgi vesicles, plastids, and vacuoles (Buckeridge et al. 1999; Etxeberria and Gonzales 2003; Koch 2004), but also to actin proteins in the cytosol (Winter and Huber 2000; Winter et al. 1998). SUS has also been detected in mitochondria, where its function remains unclear (Subbaiah et al. 2006).

Many plant SUS-encoding genes (Sus genes) have been isolated and characterized (Sturm and Tang 1999). Sus genes belong to a small multigenic family in both monocot and dicot plants (Komatsu et al. 2002). Six Sus genes have been isolated from Arabidopsis and three from maize (Baud et al. 2004; Duncan et al. 2006). According to their intron/exon structure and size, Sus genes are organized into four phylogenetic groups, including a monocot SUS group, a dicot SUS1 group, a SUSA group, and a "new group" (Bieniawska et al. 2007; Komatsu et al. 2002; Harada et al. 2005). Unlike the genes of the SUSA group, many $S u s$ genes belonging to the SUS1 group are induced by anoxia (Baud et al. 2004; Harada et al. 2005). In addition, sugar-responsive elements have been identified in Sus gene promoters (Grierson et al. 1994; Martin et al. 1993) and it is commonly observed that Sus genes from a given plant species are differently regulated by sugars (Koch et al. 1992). In contrast, few data are available on the implication of growth regulators in Sus gene regulation (Harada et al. 2005).

In the present study, we identified PrSusl, a gene belonging to the dicot SUS1 group (PrSus 1) and isolated from the parasitic plant $P$. ramosa. Several experiments using different types of molecular and microscopy techniques revealed the spatial and temporal regulation of PrSusl during the infection process in addition to its upregulation by the host-derived auxin. Taken together, these results provide a useful foundation for understanding the role of PrSus1 in cellulose synthesis in meristematic areas and vascular tissues of the parasitic plant $P$. ramosa.

\section{RESULTS}

\section{Isolation of PrSus1 cDNA from $P$. ramosa.}

PrSUS1-encoding cDNA was obtained by reverse-transcriptase polymerase chain reaction (PCR) using sets of primers designed from conserved regions of plant SUS sequences. Using rapid amplification of cDNA ends (RACE) strategies, a fulllength cDNA (2,786 bp) (accession number JN048797) was isolated. The PrSusl sequence encodes an 806-amino-acid protein, with a predicted molecular mass of $92.1 \mathrm{kDa}$, and shares the highest identity with two SUS proteins from Solanum lycopersicum (CAA09593, 88\%) (Fuglevand et al. 1998) and Coffea arabica (CAJ32596, 87.8\%) (Geromel et al. 2006). It presents a serine residue in the N-terminal region (Ser 11) which is conserved in most SUS proteins (Winter and Huber 2000). PrSUS1 features two SUS characteristics: an Nterminal extension and a glycosyl transferase group 1 domain. PrSUS1 also has a signal peptide for mitochondria. A phylogenetic analysis (data not shown) clustered PrSUS1 with the abovementioned $S$. lycopersicum and $C$. arabica SUS in the dicot SUS1 group (Komatsu et al. 2002).

\section{Development-related changes in PrSus1 gene expression.}

Patterns of gene expression were analyzed using real-time quantitative (q)PCR in a range of organs and stages of the parasite development previously described by Draie and associates (2011). Accumulation of PrSusl transcripts was expressed relative to the transcript level of the constitutive elongation factor 1- $\alpha$ gene (PrEFl $\alpha 1$ ) (Fig. 1). PrSusl transcripts accumulated strongly in $P$. ramosa tissues once the parasite had attached to host roots. Accordingly, transcript levels were much higher in both tubercles and shoots than in germinated seed. Nevertheless, a gradual decline in PrSus 1 transcript accumulation was observed during the parasitic phase, from the highest level in young tubercles (Tub.III) and the lowest in emerged and flowering shoots (FS.V), particularly in developing fruit (F.V). Concerning PrSus 1 expression in seed, germinated seed exhibited higher PrSusl transcript levels than preconditioned seed.

\section{Tissue-specific expression} of PrSus1 and SUS immunolocalization.

Because they displayed high accumulation in PrSusl transcripts (Fig. 1), young tubercles (Tub.III) (Fig. 2A and D) were chosen for in situ hybridization experiments from longitudinal sections of adventitious root and shoot apical meristems. Positive hybridization (purple stain) with the specific antisense probe indicated PrSusl transcript accumulation (Fig. 2C, F, and $\mathrm{H}$ ), whereas no signal was observed after hybridization with the sense probe (Fig. 2B, E, and G). Transcripts accumulated strongly in both shoot and root apices (Fig. 2C and F). In contrast, no staining was detected in the starch-accumulating parenchyma of tubercles (Fig. 2C). In shoot apices, PrSus 1 mRNA accumulated in various tissues, including the medullary

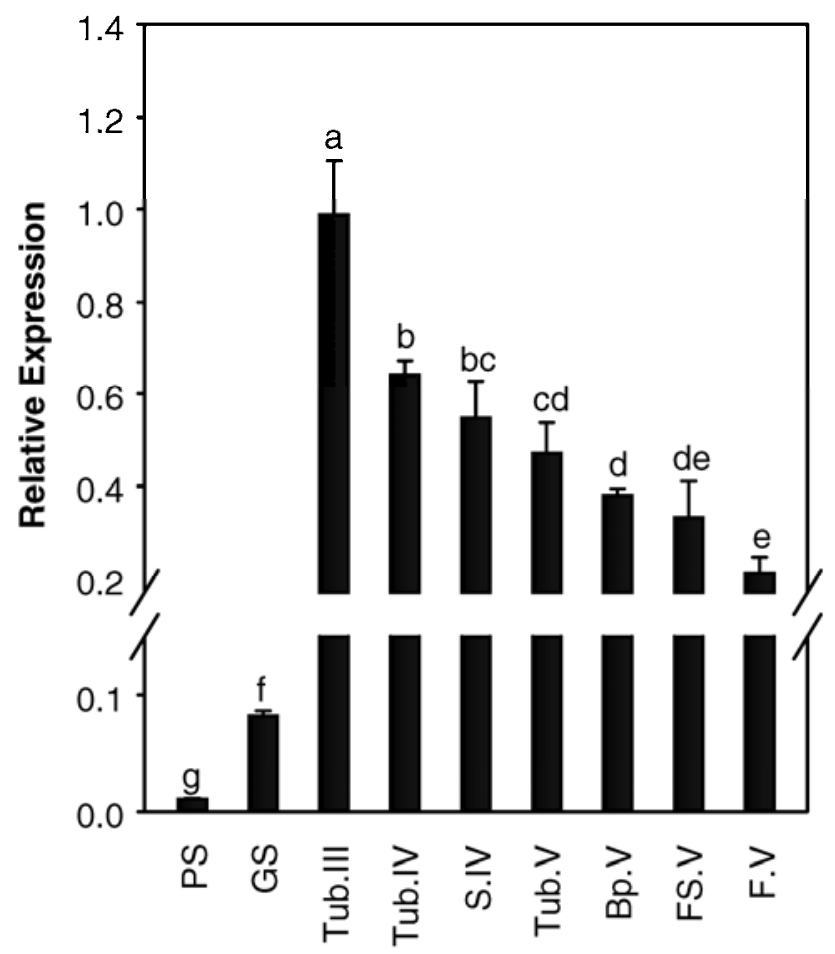

Fig. 1. Development-related changes in the levels of PrSus1 transcripts in Phelipanche ramosa. Transcript accumulation is expressed relative to PrEF $1 \alpha 1$ transcript levels. Data are means \pm standard error $(n=3)$. Values with the same letter are not significantly different (analysis of variance, SNK test, $P<0.05$ ). Preparasitic stages: preconditioned seed (PS) and germinated seed (GS); parasitic stages following attachment to tomato roots: growing tubercle (Tub.III); tubercle (Tub.IV) bearing the growing subterranean shoot (S.IV); tubercle (Tub.V) bearing the emerged flowering shoot; growing flowering shoot (apical part) (FS.V), and flowering shoot bearing developing fruits (F.V). Basal part (Bp.V) does not bear flowers and is larger and more fibrous than the flowering shoot (Draie and associates 2011). 
meristem of the shoot apical meristem and vascular tissues of scale leaves and the stem (Fig. 2C). In root apices, in addition to the root apical meristem, differentiating xylem-conducting elements exhibited high accumulation of PrSus 1 mRNA (Fig. $2 \mathrm{~F}$ and $\mathrm{H}$ ). In contrast, mature xylem elements from basal parts of adventitious roots did not exhibit PrSus 1 mRNA accumulation (data not shown).
To complement in situ hybridization, SUS immunolocalization was performed on young tubercles (Tub.III) using an antibody raised against a denatured Vicia faba SUS (Ross and Davies 1992). Although labeling was absent in cross-sections probed with pre-immune serum (Fig. 3A), strong SUS labeling matched cell-wall thickening of xylem elements (Fig. 3B and C).
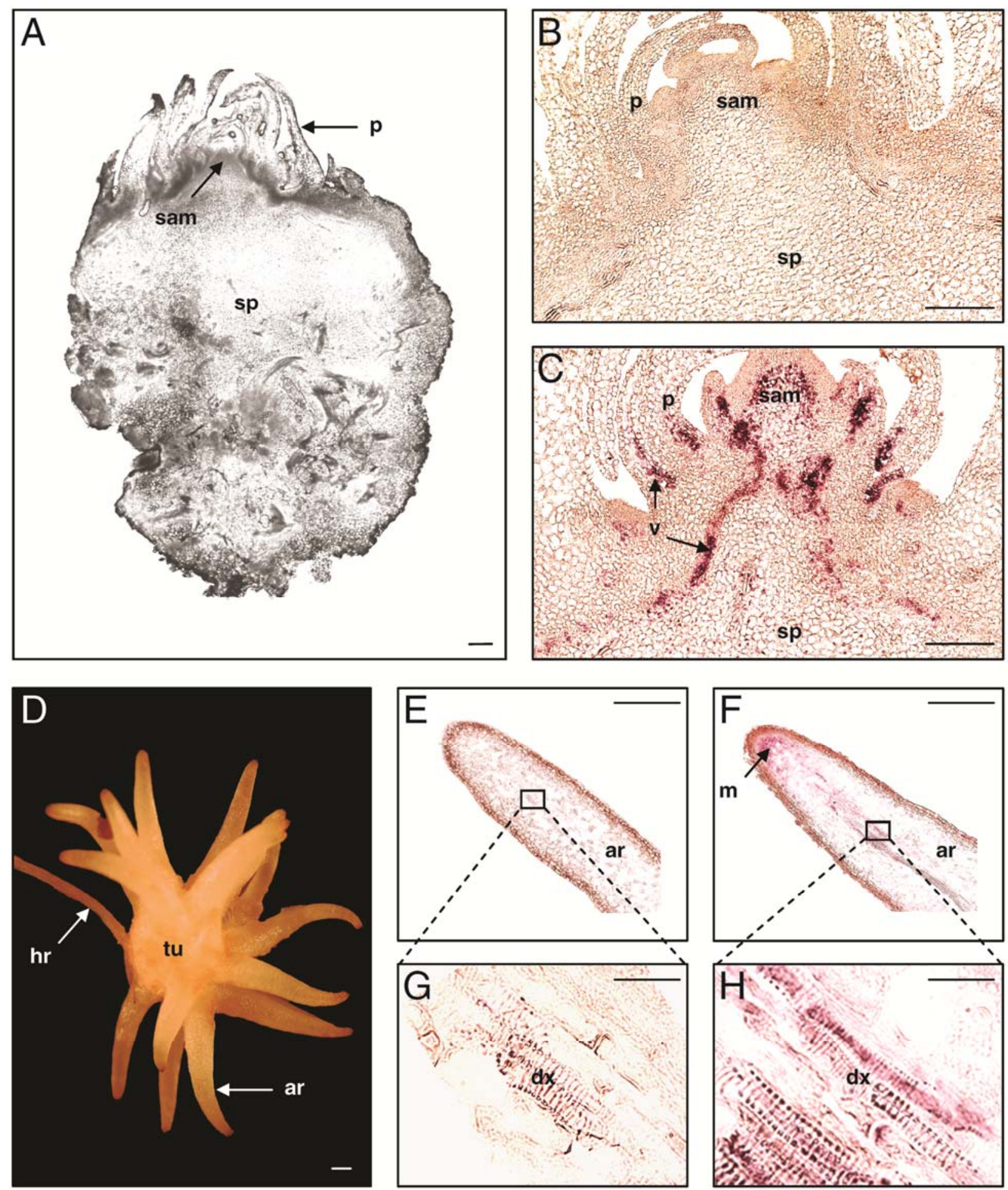

Fig. 2. In situ localization of PrSus1 transcripts in adventitious roots and the apical bud of young Phelipanche ramosa tubercles. A, Longitudinal section of a young tubercle (Tub.III). C, F, and $\mathbf{H}$, Sections (10 $\mu \mathrm{m}$ thick) hybridized with antisense probe specific to PrSus $1 \mathrm{mRNA}$. B, E, and $\mathbf{G}$, Sections hybridized with sense probe as a negative control. Positive hybridization signals are indicated by violet staining using a digoxigenin-labeled RNA immunodetection system. D, Young tubercle (Tub.III) attached to host root. Ar = adventitious root; $\mathrm{dx}=$ developing $\mathrm{xylem} ; \mathrm{hr}=$ host root; $\mathrm{m}=$ meristem; $\mathrm{mx}=\mathrm{mature} \mathrm{xylem} ; \mathrm{p}=\mathrm{scale-leaf}$ primordium; sam = shoot apical meristem; $\mathrm{sp}=$ storage parenchyma; tu = tubercle; $\mathrm{v}=$ vascular tissues. Scale bars: A-F, $500 \mu \mathrm{m} ; \mathrm{G}$ and H: $36 \mu \mathrm{m}$. 
Isolation and sequence analysis of the PrSus1 promoter.

A 2,175-bp 5'-flanking DNA fragment of the PrSus1 gene was isolated by PCR amplification of a P. ramosa GenomeWalker library. The 5'-RACE analysis allowed the identification of a potential transcription start site $(+1)$ of PrSus 1 . Nucleotide sequence comparison between the PrSusl cDNA and the partial PrSusl genomic sequence revealed that a 791-bp intron sequence was present in the 196-bp fragment of the $5^{\prime}$ untranslated region. The structure of the PrSus1 promoter (accession number JN204913) is shown in Figure 4. A TATA-box
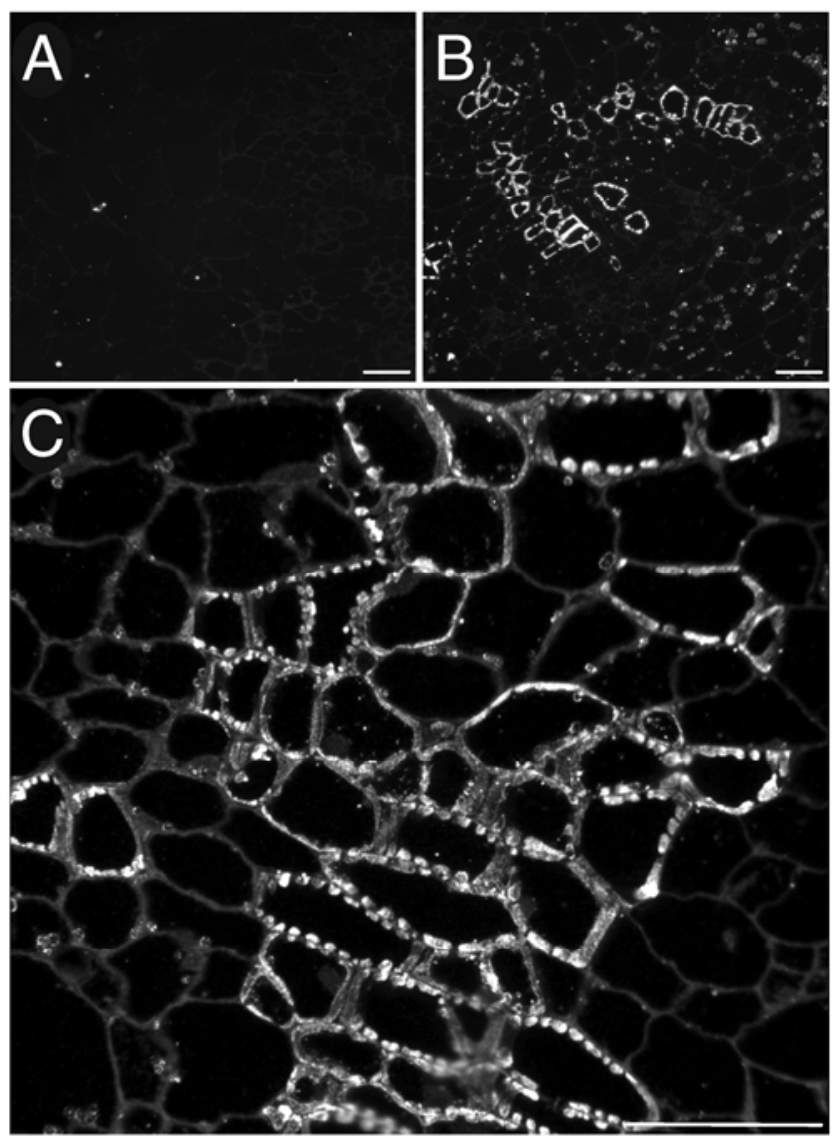

Fig. 3. Sucrose synthases (SUS) distribution in Phelipanche ramosa tubercles visualized using immunofluorescence microscopy. Cross-sections of a resin-embedded young tubercle (Tub.III): A, section probed with the preimmune serum; $\mathbf{B}$ and $\mathbf{C}$, sections probed with anti-Vicia faba SUS antibodies (Ross and Davies 1992). Sections were probed with Alexa-conjugated second antibodies (signal appears in white). Excitation light, 450- to 490-nm band-pass filter; emission light, >515 nm. Scale bars, $50 \mu \mathrm{m}$. sequence was located between nucleotides -34 and -28 , and the closest CAAT-box sequence was located between -318 and -315. A promoter motif search using PLACE software (Higo et al. 1999) identified a number of putative auxin regulatory motifs, including an ACTTTA motif (NTBBF1), an auxin-regulated expression element that is required for tissue-specific expression in the meristem and vascular system (Baumann et al. 1999), and a TGACG motif corresponding to the auxinregulated expression element ASF1 (Klinedinst et al. 2000) (Fig. 4).

\section{Control of PrSus1 expression by host-derived auxin.}

To validate possible PrSusl control by auxin, the auxin transfer from host to parasite was manipulated by inhibiting polar auxin transport in host stem by applying 2,3,5-triiodobenzoic acid (TIBA), as previously described by Harb and associates (2004). Impact of the treatment on the expression of PrSusl and two auxin-signaling markers, IPT and CCD7 genes, was analyzed. First, the auxin-responsive sequences PrCCD7 and PrIPT, orthologous to pea (Johnson et al. 2006; Shimizu-Sato et al. 2009), were isolated from $P$. ramosa (accession numbers JN412814 and JN412815, respectively). As expected, PrIPT and PrCCD7 genes were 3.6-fold induced and 5.9-fold repressed, respectively, in parasite tubercles growing on TIBA-treated host plants (Fig. 5). These findings indicate a decrease in auxin signaling in the parasite in response to TIBA. Interestingly, a threefold repression was also observed for PrSusl in tubercles growing on TIBA-treated host plants (Fig. 5), suggesting that $\operatorname{PrSusl} 1$, like $\operatorname{PrCCD7}$, is upregulated by host-derived auxin.

\section{DISCUSSION}

Once attached to host roots, achlorophyllous parasitic plants such as broomrapes must take up sucrose from the host plant (Abbes et al. 2009; Aber et al. 1983). As recently shown by Draie and associates (2011), sucrose unloading in $P$. ramosa is facilitated by rapid hydrolysis of the disaccharide mediated by the dominant PrSAI1 invertase. Nevertheless, this finding did not preclude a significant role of SUS in sucrose utilization in the parasite.

Using degenerate primers corresponding to highly conserved regions of plant Sus genes, we succeeded in isolating the PrSus 1 cDNA from $P$. ramosa, which shared some typical traits with plant SUS-encoding genes (Winter and Huber 2000). The deduced amino acid sequence includes a highly conserved serine residue in the $\mathrm{N}$-terminal region (Ser 11) and two characteristics revealed by National Center for Biotechnology Information Conserved Domain Search: an N-terminal extension of SUS and a glycosyl transferase group 1 domain.

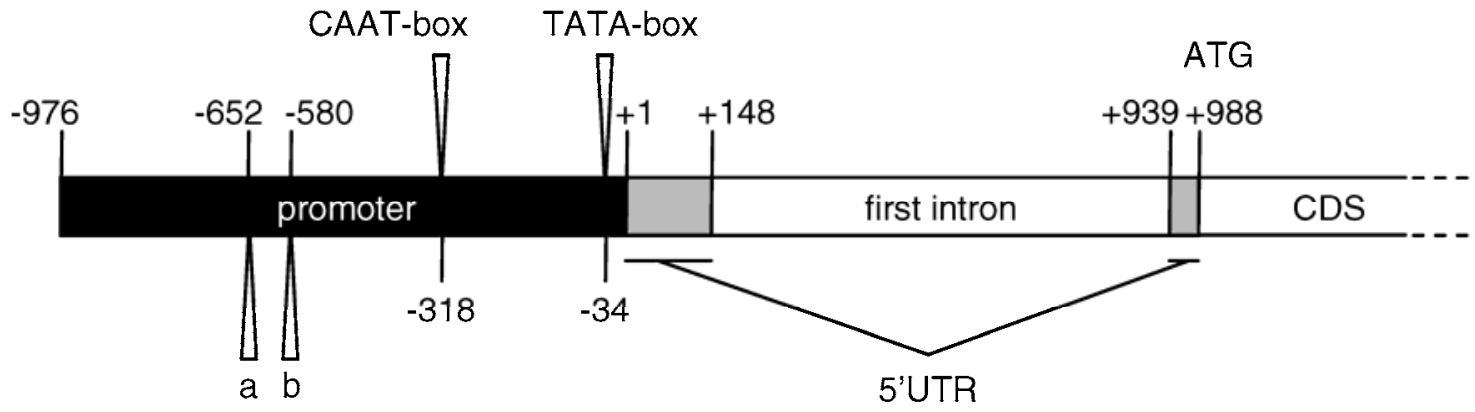

Fig. 4. Auxin-responsive elements present in PrSus1 promoter. A schematic diagram of the structure of the PrSus 1 gene with promoter, $5^{\prime}$ untranslated region (5'UTR), first intron, partial coding sequence (CDS), TATA-box, CAAT-box, and transcription start site (+1). An analysis using PLACE software (Higo et al. 1999) identified auxin-responsive elements in the PrSus 1 promoter. a, Auxin-responsive elements corresponding to an NTBBF1 motif (ACTTTA). b, Auxin-responsive elements corresponding to an ASF1 motif (TGACG). 
Its size of $92.1 \mathrm{kDa}$ is typical of the monomeric form of SUS (approximately $90 \mathrm{kDa}$ ). According to the protein sequence, PrSUS1 belongs to the dicot SUS1 group (Komatsu et al. 2002). Both tubercles and shoots express PrSusl throughout parasite development (Fig. 1). Nevertheless, developing tubercles accumulate the highest level of transcripts (Tub.III), specifically in cellulose-synthesizing tissues of adventitious root apices and shoot apical buds, including the meristem and maturing vascular elements (Fig. 2). This distribution is consistent with the presence of an ACTTTA motif (NTBBF1) in the PrSus 1 promoter (Fig. 4); this motif is required for specific expression in meristems and vascular systems (Baumann et al. 1999). In root apices, PrSus1 expression was associated with differentiating xylem elements, in accordance with immunofluorescence microscopy experiments showing the association of the protein with secondary cell-wall thickening (Figs. $2 \mathrm{H}$ and 3). Similarly, SUS has been localized to cellulose synthesis sites in tracheary elements of Zinnia elegans, where SUS accumulated near the plasma membrane and the microtubules under the thickenings of the secondary cell wall, and also in the cell wall (Salnikov et al. 2001). In other cellulose-synthesizing tissues, such as differentiating tobacco pollen tubes, SUS has been detected in Golgi vesicles, the plasma membrane underneath secondary thickening, and mostly in the cell wall, suggesting that SUS is transferred to the cell wall by a secretion mechanism involving Golgi vesicles (Persia et al. 2008). Moreover, SUS detection in cryogenically fixed and freeze-substituted cotton fibers (Ruan 2007; Salnikov et al. 2003) provides further support for a cell wall location of SUS in plants, acting during the synthesis of cell wall elements in association with callose synthase and cellulose synthase (Amor et al. 1995; Coleman et al. 2009; Gardiner et al. 2003). All of these findings suggest that PrSUS1 is involved in cellulose synthesis in the secondary thickenings of differentiating xylem elements in tubercles and adventitious roots of $P$. ramosa. As

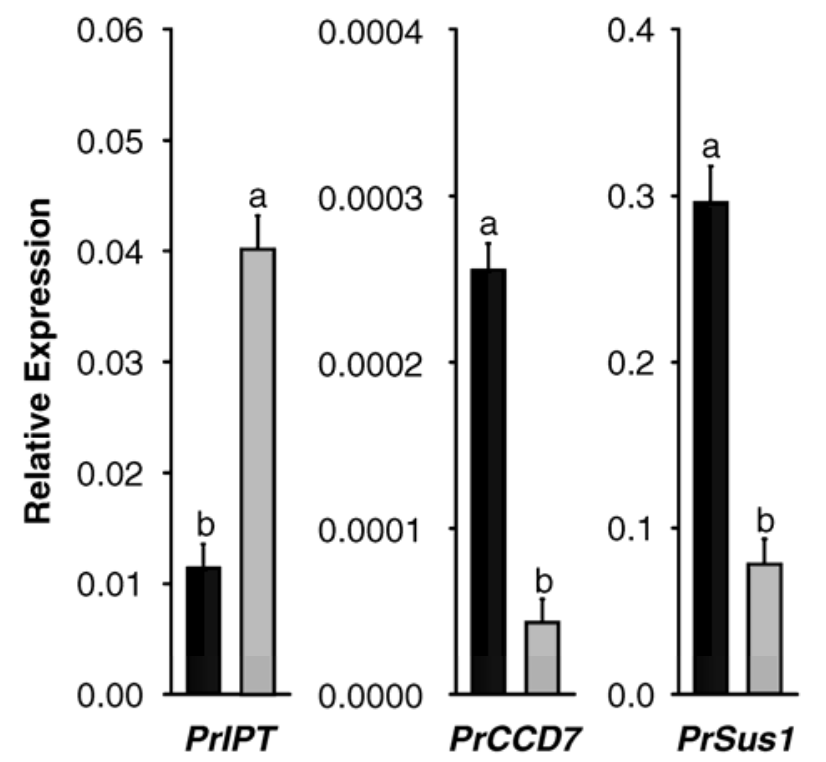

\section{- Lanolin $\square$ Lanolin + TIBA}

Fig. 5. Effect of host plant (tomato) treatment with triiodobenzoic acid (TIBA) on the expression of two auxin-responsive genes (PrIPT and PrCCD7) and PrSus1. Young tubercles (Tub.III) were harvested 3 weeks after treatment with TIBA (10 $\mathrm{mg} \mathrm{g}^{-1}$ of lanolin). Transcript accumulation is expressed relative to $\operatorname{PrEF} 1 \alpha 1$ transcript levels. Data are means \pm standard error $(n=3)$. For each gene, values with the same letter are not significantly different (analysis of variance, SNK test, $P<0.05$ ). observed for Sus4 in tomato (Pien et al. 2001), PrSusl is also highly expressed in maturing vascular tissues of the shoot apical bud, in which xylem and phloem are sorely distinguished. Thus, PrSUS1 is probably crucial for cell wall integrity of both xylem and phloem tissues in the apical bud. In addition, because vascular tissues were not observed in radicles of germinated seed (Aber and Sallé 1983), the enhanced PrSusl expression observed in germinated seed in comparison with preconditioned seed may be related to cellulose enrichment in elongating radicles (Fig. 1).

Additional roles have been proposed for PrSUS1, including energy efficiency in meristems (Koch 2004) and starch deposition in plastids (Baroja-Fernández et al. 2009). Our findings do not preclude PrSUS1 from being the dominant enzyme for sucrose breakdown in meristematic cells. The presence of PrSUS1 is more likely related to the lower energy consumption in root and shoot apical meristems, because they strongly express PrSus1 (Fig. 2C and F). However, PrSUS1 is probably not involved in starch deposition because no PrSus1 transcript accumulation was observed in the starch-accumulating parenchyma of tubercles (Fig. 2C).

Although hormonal control of invertases is well documented (Ehness and Roitsch 1997; Sokolova et al. 2002), information on SUS is rare. Harada and associates (2005) show a positive correlation between stem elongation and the level of PdSUS1 transcripts in turions of Potamogeton distinctus treated with synthetic auxin 2,4D and under anoxia. This correlation suggests that $P d S U S 1$ is upregulated by auxin. In the present study, two major findings suggest that PrSus 1 is also regulated by auxin. First, PrSusl is expressed strongly in auxin-rich tissues, including germinated seed (Fig. 1), meristems, and differentiating xylem elements (Fig. 2C, F, and H). Auxin production in germinating Phelipanche ramosa seed has been demonstrated by Slavov and associates (2004). In parallel, the role of auxin in vascular maturation and xylem differentiation is well documented in plants (Ohashi-Ito and Fukuda 2010; Yoshida et al. 2009). Developing P. ramosa tubercles exhibit root formation and disorganized vascular differentiation (Fig. 2A and D). These traits have also been described in the interaction between $P$. ramosa calli and tomato (Zhou et al. 2004), and are indicative of high auxin concentrations (Sachs 1991) in accordance with the fact that the tubercle acts as a strong sink for host-derived auxin (Bar-Nun et al. 2008). Second, inducing auxin deprivation of the parasite by growing them on TIBA-treated host plants, Harb and associates (2004) demonstrated that xylem differentiation in the parasite is controlled by host-derived auxin. We show that similar TIBA treatment of the host plant led to significant repression of PrSus1 in tubercles (Fig. 5), suggesting that PrSus 1 is an auxin-responsive gene implicated in the maturation of xylem elements in $P$. ramosa. Changes in auxin response in tubercles has been demonstrated using two auxinregulated genes as controls, the genes PrIPT and PrCCD7 encoding an adenosine phosphate iso-pentenyl-transferase and a carotenoid cleavage dioxygenase, respectively (Brewer et al. 2009; Miyawaki et al. 2006; Tanaka et al. 2006). In pea, auxin derived from the shoot apex controls bud outgrowth by repressing PsIPT2 and inhibiting local cytokinin biosynthesis in the nodal stem (Shimizu-Sato et al. 2009). Moreover, pea has two IPT genes, PSIPT1 and PSIPT2, and both are markedly induced in the nodal stem following auxin depletion in response to decapitation (Tanaka et al. 2006). The gene $C C D 7$ is involved in the synthesis of strigolactones (GomezRoldan et al. 2008; Umehara et al. 2008), which interact with auxin in shoot branching control. The genes rms5 and $M A X 3$ - orthologous to $C C D 7$ in pea and Arabidopsis, respectively-are highly repressed following decapitation or 
inhibition of the auxin polar transport (Hayward et al. 2009; Johnson et al. 2006). Finally, the in silico analysis of PrSus1 promoter revealed putative auxin-regulated expression elements NTBBF1 (Baumann et al. 1999) and ASF1 (Klinedinst et al. 2000) (Fig. 4). Their signification in auxin responsiveness needs additional investigations. Auxin controls xylem cell development in plants through direct and indirect pathways (Ohashi-Ito and Fukuda 2010; Yoshida et al. 2009). Although our study did not focus on xylogenesis control, it provides new insights into the auxin-mediated control of cellulose enrichment of secondary walls. Indeed, as attested by the presence of two auxin-regulated expression elements in the PrSusl promoter (Fig. 4) and the downregulation of PrSusl in parasites growing on TIBA-treated tomato plants (Fig. 5), the present study reveals, for the first time, an SUSencoding gene that acts as an auxin-responsive gene in xylem differentiation in plants. Interestingly, there is some evidence that auxin can also induce cellulose synthase ( $C e S A)$-encoding genes in Arabidopsis and Z. elegans through the presence of auxin-response elements in the CeSA promoter (Goda et al. 2004; Wu et al. 2009). The hypothesis that auxin may induce both cellulose synthases and the collaborating SUS to promote cellulose production in maturing vascular tissues in plants has not yet been tested.

Within the host-parasite interaction, we demonstrated that PrSusl is under the control of host-derived auxin. Given that polar auxin transport participates in the formation of a continuous vascular strand (Sachs 1991) and that the parasite acts as a strong sink for auxin (Bar-Nun et al. 2008), the formation of a continuous vascular strand between the host and the parasite and the differentiation of xylem elements in the parasite are under the control of the polar auxin transport in the host plant (Bar Nun et al. 2008; Harb et al. 2004). Consequently, the disruption of the auxin relationships between host and parasite through PrSusl inhibition may prevent parasite development. No genetic transformation tools have been developed for broomrapes; therefore, reverse genetics cannot be carried out to confirm the roles of PrSusl in the parasite. However, nucleic acids can be transferred between host and parasite through the phloem (Davis and Wurdack 2004; Westwood et al. 2009) and parasitic plant gene expression can be silenced by modifying host genes (Aly et al. 2009; Tomilov et al. 2008). Thus, PrSus1silencing experiments are potential avenues for exploring the involvement of PrSus1 in the establishment of the host-parasite interaction.

\section{MATERIALS AND METHODS}

\section{Plant materials, cultivation, treatments, and sampling.}

Seed were collected from flowering spikes of $P$. ramosa $\mathrm{L}$. Pomel in France (Saint Jean d'Angely station, 2005) and stored in darkness at $25^{\circ} \mathrm{C}$ until use.

For molecular analyses on $P$. ramosa seed, seed were surfacesterilized as described by Labrousse and associates (2001). They were preconditioned on sterile, watered, glass fiber filters placed in 9-cm-diameter petri dishes for 7 days in darkness at $21^{\circ} \mathrm{C}$. Preconditioning was carried out in water. Germination was induced by adding GR24 (1 $\left.\mu \mathrm{g} \mathrm{liter}^{-1}\right)$, a synthetic germination stimulant (Johnson et al. 1976).

Two-week-old tomato seedlings, previously cultivated in petri dishes, were transplanted into hydroponic co-culture systems to facilitate confrontation between tomato roots and $P$. ramosa GR24-germinated seed, as described previously (Lejeune et al. 2006). Inhibition of IAA polar transport by TIBA in host tomato plants was carried out following Harb and associates (2004). TIBA in lanolin (10 $\mathrm{mg} \mathrm{g}^{-1}$ [wt/wt]) was used by pasting a ring on the base of tomato seedlings 4 weeks after the transplanting date into the hydroponic co-culture systems. Plants pasted with lanolin alone served as controls. Developing $P$. ramosa tubercles were harvested after 3 weeks of treatment.

All the plant materials were immediately frozen in liquid nitrogen and stored at $-80^{\circ} \mathrm{C}$ prior to RNA extraction. Tissue samples for histological purposes were extemporaneously harvested.

\section{Sample preparation and immunofluorescence labeling.}

Young tubercles (Tub. III) were fixed overnight at $4^{\circ} \mathrm{C}$ in a mixture of $3 \%(\mathrm{wt} / \mathrm{vol})$ paraformaldehyde and $0.5 \%$ (vol/vol) glutaraldehyde in $0.1 \mathrm{M}$ phosphate buffer ( $\mathrm{pH}$ 7.2). Fixed samples were rinsed using buffer and deionized water prior to dehydration through successive baths in $30,50,70,85,95$, and $100 \%$ ethanol solutions. Samples were successively impregnated with 80/20, 60/40, 40/60, 20/80, and 0/100 (vol/vol) ethanol/London Resin White (SPI Supplies/Structure Probe, Inc., West Chester, PA, U.S.A.). The impregnated samples were then embedded in gelatin capsules and polymerized for $24 \mathrm{~h}$ at $55^{\circ} \mathrm{C}$.

Semithin resin sections ( $1 \mu \mathrm{m}$ thick) were collected on multiwell glass slides pretreated with Vectabond (British BioCell International, Cardiff, U.K.). Sections were successively incubated at room temperature in a blocking solution $(3 \%$ [wt/vol] bovine serum albumin [BSA] and $0.1 \mathrm{M}$ Na-phosphate buffer saline [PBS], pH 7.2) for $30 \mathrm{~min}$ and in solution containing primary antibodies raised against a denatured $V$. faba SUS (dilution 1:100 [vol/vol]) (Ross and Davies 1992) for $1 \mathrm{~h}$. Sections were then incubated for $1 \mathrm{~h}$ in a solution of goat antirabbit immunoglobulin G Alexa 488-secondary antibody conjugates (dilution 1:100 [vol/vol]) (Life Technologies Corporation, Carlsbad, CA, U.S.A.). Antibodies were diluted in PBS containing $1 \%$ (wt/vol) BSA and $0.05 \%$ (wt/vol) Tween-20. Controls were performed using pre-immune serum instead of anti-SUS antibody at the same dilution.

Sections were examined using a Leica DMRD microscope equipped with epifluorescence (Leica Microsystems Wetzlar $\mathrm{GmbH}$, Wetzlar, Germany). A 450- to 490-nm band-pass filter was used as excitation light, the fluorescence being detected above $515 \mathrm{~nm}$.

\section{Preparation of digoxigenin-labeled RNA probes for in situ hybridization.}

Digoxigenin (DIG)-labeled RNA probes were prepared using an in vitro transcription kit (Riboprobe Combination Systems; Promega, Charbonnières-les-Bains, France) according to the manufacturer's instructions. The riboprobes were synthesized from the full-length PrSus1 clones. Antisense and sense probes were transcribed from SP6 or T7 RNA polymerase promoters after linearization of the vector with ApaI or NdeI, respectively. Full-length probes were treated by alkaline hydrolysis, as described previously by Winzer-Serhan and associates (1999), thus producing 250-bp fragments.

\section{Sample preparation and in situ hybridization.}

Young tubercles (Tub.III) were fixed on ice under vacuum in $4 \%(\mathrm{wt} / \mathrm{vol})$ paraformaldehyde in $1 \times \mathrm{PBS}(\mathrm{pH} 7)$ for $3 \mathrm{~h}$ and then kept in fixative buffer overnight at $4^{\circ} \mathrm{C}$. Once fixed, samples were washed, dehydrated slowly with ethanol as previously described, exchanged with Histochoice (Sigma, SaintQuentin Fallavier, France), then embedded in paraffin. Sections $(10 \mu \mathrm{m})$ were mounted on Polysine slides (VWR International, Strasbourg, France) and dried at $37^{\circ} \mathrm{C}$ overnight. Paraffin was removed through two successive 10 -min baths in Histochoice. After an additional 15-min bath in methanol, slides were progressively hydrated in ethanol series $(100,95,70,50$, and $30 \%$ ) and then treated with successive baths: water ( $2 \mathrm{~min}), 1 \times$ 
PBS (2 min), 0.2 M HCl (20 min), water ( $2 \mathrm{~min}), 2 \times \mathrm{SSC}(1 \times$ $\mathrm{SSC}$ is $0.15 \mathrm{M} \mathrm{NaCl}$ plus $0.015 \mathrm{M}$ sodium citrate) (20 min), and water $(2 \mathrm{~min})$. Slides were treated with proteinase $\mathrm{K}$ (Sigma) at $10 \mu \mathrm{g} \mathrm{ml}^{-1}$ in $1 \times \mathrm{PBS}$ for $30 \mathrm{~min}$ at $37^{\circ} \mathrm{C}$, incubated in $1 \times$ PBS for 2 min at room temperature, fixed in $3.7 \%$ formaldehyde for $10 \mathrm{~min}$, acetylated using $0.5 \%$ acetic anhydride in $0.1 \mathrm{M}$ triethanolamine for $10 \mathrm{~min}$, and then rinsed in $1 \times \mathrm{PBS}$. Sections were dehydrated in ethanol series before hybridization. Sections were hybridized with equal concentrations $\left(1 \mathrm{ng} \mu \mathrm{l}^{-1}\right)$ of either sense or antisense probes in $1 \times$ Denhardt's (Sigma), $10 \%$ dextran sulfate, tRNA at $200 \mu \mathrm{g} \mathrm{ml}^{-1}, 50 \%$ formamide, RNasin (Roche Diagnostics, Meylan, France) at $10 \mathrm{U} \mathrm{ml}^{-1}, 1 \times$ salts $(10 \mathrm{mM}$ Tris-HCl, $\mathrm{pH} 8.0$, containing $300 \mathrm{mM} \mathrm{NaCl}$ and $1 \mathrm{mM}$ EDTA), and incubated at $55^{\circ} \mathrm{C}$ overnight in a wet chamber. Sections were washed twice in $50 \%$ formamide in $1 \times \mathrm{SSC}$ for $2 \mathrm{~h}$ at $55^{\circ} \mathrm{C}$, rinsed in NTE $(10 \mathrm{mM}$ Tris- $\mathrm{HCl}, \mathrm{pH} 8.0$, containing $0.5 \mathrm{M} \mathrm{NaCl}$ and $5 \mathrm{mM}$ EDTA), incubated with RNase A (Fermentas GmbH, Villebon-sur-Yvette, France) at $10 \mu \mathrm{g}$ $\mathrm{ml}^{-1}$ in NTE for $30 \mathrm{~min}$ at $37^{\circ} \mathrm{C}$, washed three times in NTE for $5 \mathrm{~min}$ at $37^{\circ} \mathrm{C}$, placed in $50 \%$ formamide in $0.5 \times \mathrm{SSC}$ for 1 $\mathrm{h}$ at $55^{\circ} \mathrm{C}$, and then washed at room temperature in $1 \times \mathrm{PBS}$. Sections were successively incubated at room temperature in a blocking solution $(0.5 \%$ [wt/vol] blocking reagent [Roche Diagnostics] $0.3 \%$ [vol/vol] Triton X100, $100 \mathrm{mM}$ Tris- $\mathrm{HCl}$ [pH 7.5], and $150 \mathrm{mM} \mathrm{NaCl})$ for $45 \mathrm{~min}$, in buffer A (100 mM Tris- $\mathrm{HCl}[\mathrm{pH} 7.5]$ containing $1 \%$ [wt/vol] BSA, $0.3 \%$ [vol/vol] Triton $\mathrm{X} 100$, and $150 \mathrm{mM} \mathrm{NaCl}$ ) for $45 \mathrm{~min}$, probed with antiDIG serum (Roche Diagnostics) diluted 1:1000 in buffer A for $1 \mathrm{~h}$ in a wet chamber, washed three times in buffer A for 20 min each, and then three times in detection buffer $(100 \mathrm{mM}$ Tris- $\mathrm{HCl}, \mathrm{pH} 9.5$, containing $50 \mathrm{mM} \mathrm{MgCl}_{2}$ and $100 \mathrm{mM}$ $\mathrm{NaCl}$ ) for 5 min each. Sections were incubated in a nitroblue tetrazolium/5-bromo-4-chloro-3-indolyl phosphate solution at $20^{\circ} \mathrm{C}$. After suitable color development, reaction was stopped by rinsing in water and sections were mounted in aquatex (Merck, Strasbourg, France).

\section{Extraction of total RNA and cDNA preparation.}

Frozen tissues were ground in liquid nitrogen and total RNA was extracted using the RNeasy plant mini kit (Qiagen, Courtaboeuf, France) according to the manufacturer's instructions. Extracts were treated with DNase I enzyme $\left(0.02 \mathrm{U}^{-1}\right)$
(New England Biolabs, Ipswich, MA, U.S.A.). Integrity of the total RNA was checked by electrophoresis on $1 \%$ (wt/vol) agarose gel. RNA was quantified spectrophotometrically (A260/280, NadoDrop Spectrophotometer ND-1000; Labtech International Ltd, Ringmer, U.K.). Using oligo (dT20) as a primer, cDNA was prepared from samples $(0.5 \mu \mathrm{g})$ of total RNA using the Superscript II Reverse Transcriptase kit (Life Technologies Corporation, Carlsbad, CA, U.S.A.).

\section{Molecular cloning of $P$. ramosa cDNAs.}

The cDNAs isolated from a flowering shoot (FS.V) were used for PCR amplifications. Degenerate primers corresponding to highly conserved regions were designed (Table 1). After denaturation at $94^{\circ} \mathrm{C}$ for $5 \mathrm{~min}$, amplification consisted of 35 cycles of $45 \mathrm{~s}$ at $94^{\circ} \mathrm{C}, 45 \mathrm{~s}$ at $55^{\circ} \mathrm{C}$, and $1.5 \mathrm{~min} 30 \mathrm{~s}$ or $45 \mathrm{~s}$ at $72^{\circ} \mathrm{C}$ for PrSus1. A final step of elongation was done at $72^{\circ} \mathrm{C}$ for $5 \mathrm{~min}$. The amplified DNA fragment was purified and cloned into a pGEM-T Easy vector (Promega). Recombinant plasmid DNA was prepared and then sequenced by GATC Biotech (Konstanz, Germany). Based on the initial PrSusl sequence information, new primers were generated for RACE of each fragment using the Generacer kit (Life Technologies Corporation). RACE products corresponding to the SUS-encoding gene were cloned and sequenced. To amplify full-length cDNA, specific primer pairs were designed (Table 1). For PrIPT and PrCCD7 cloning, a similar strategy was used (Table 1).

\section{Real-time qPCR.}

The determined sequences were used to design gene-specific primers for real-time qPCR. Six primer pairs were designed (maximum length, $150 \mathrm{bp}$; optimal melting temperature, $60^{\circ} \mathrm{C}$; GC percentage between 30 and 80\%) with Primer Express 3.0 software (Applied Biosystems, Foster City, CA, U.S.A.) (Table 1). The selected primers underwent an extensive search using the BLAST tool to avoid any significant homology with other known nucleotide sequences.

qPCR using SYBR Green technology was carried out on the Applied Biosystems 7300 real-time PCR system. Each reaction contained $300 \mathrm{nM}$ each primer, $5 \mu \mathrm{l}$ of cDNA sample (approximately $5 \mathrm{ng}$ of input RNA), and $2 \times$ Power SYBR Green PCR Master Mix (Applied Biosystems) in a total volume of $25 \mu \mathrm{l}$. Thermal cycling was performed using the following cycling

Table 1. Primer pairs used in this study ${ }^{\mathrm{a}}$

\begin{tabular}{|c|c|c|c|c|}
\hline Gene & Primer & Forward and reverse primers $5^{\prime} \rightarrow 3^{\prime}$ & Size (bp) & Application \\
\hline \multirow[t]{2}{*}{ PrSus1 } & SUS fwd deg & GGN GTN SAN TTY CTN AAY MGN CA & 1,570 & Partial cDNA cloning \\
\hline & SUS rev deg & ACN GTN ARN CCR AAN GCY TCR TA & & $\ldots$ \\
\hline \multirow[t]{2}{*}{$\operatorname{PrIPT}$} & IPT fwd deg & GGH GCH ACH GGN DCN GGV AAR TC & 295 & $\ldots$ \\
\hline & IPT rev deg & GCN TSN AYG WAN GAR TTN GAN CCD CC & . & $\ldots$ \\
\hline \multirow[t]{2}{*}{$\operatorname{PrCCD7}$} & CCD7 fwd deg & AAR GTK ATG AAR AAY GTK GCN AAY AC & 455 & $\ldots$ \\
\hline & CCD7 rev deg & TCN GTG AAN GCC CAR TCR TGD ATC AT & & \\
\hline \multirow[t]{2}{*}{ PrSus1 } & FL fwd Pr-SUS1 & ACC TTC AAA GGC AAA ACT CTT CAT TTG CT & 2,786 & Full-length cDNA cloning \\
\hline & FL rev Pr-SUS1 & AAC AAG AAA CTG AAT TAT TTT ATT TAT ATT AAT AC & & $\ldots$ \\
\hline \multirow[t]{2}{*}{$\operatorname{PrIPT}$} & Pr-IPT fwd & ATT CAT CAA CTC TTT CAT TAT ATA CC & 1,223 & $\ldots$ \\
\hline & Pr-IPT rev & TTC TTT ACA AAT AAG TCA TAA TAA ATT GAA & & $\ldots$ \\
\hline \multirow[t]{2}{*}{$\operatorname{PrCCD7}$} & Pr-CCD7 fwd & CAT CAC TCC CTT CGG AAC ATG CCA TGC TAA & 2,164 & $\ldots$ \\
\hline & Pr-CCD7 rev & TTT GTG TTC TTG TAC ACA ACA ACG GAT & & $\ldots$ \\
\hline \multirow[t]{2}{*}{$\operatorname{PrEF} 1 \alpha 1$} & Q-Pr-EF1 UP & TTG CCG TGA AGG ATC TGA AAC & 63 & Quantitative PCR \\
\hline & Q-Pr-EF1 DOWN & CCT TGG CAG GGT CGT CTT TA & & $\ldots$ \\
\hline \multirow[t]{2}{*}{ PrSus1 } & Q-Pr-SUS1 UP & CTC TAC GCC AAG AGT CCA AAG C & 64 & $\ldots$ \\
\hline & Q-Pr-SUS1 DOWN & TTC TGT CGC CAC CAA CTA TGA C & $\ldots$ & $\ldots$ \\
\hline \multirow{2}{*}{$\operatorname{PrIPT}$} & Q-Pr-IPT UP & CCA CCA CCT GCT CGG AAT TA & 68 & $\ldots$ \\
\hline & Q-Pr-IPT DOWN & GAG CCA TGT CGC GGA AAT & $\ldots$ & $\ldots$ \\
\hline \multirow[t]{2}{*}{$\operatorname{PrCCD7}$} & Q-Pr-CCD7 UP & TGG ACG TGG CGG CTA AAA & 63 & $\ldots$ \\
\hline & Q-Pr-CCD7 DOWN & TCT TTG GAG GCA TCT TGA ACA CT & & \\
\hline \multirow[t]{2}{*}{ PrSus1 } & Pr-SUS1-GenWalk1 & CTG TGT GCT CTT GAG AAC TTC TTG AAA AGC ATG ATC & na & Promoter cloning \\
\hline & Pr-SUS1-GenWalk2 & GAG GCT TCA AAA TTC CTT TGC CAT GGG CTT CA & $\ldots$ & $\ldots$ \\
\hline
\end{tabular}

\footnotetext{
${ }^{\mathrm{a}}$ Abbreviations: $\mathrm{PCR}=$ polymerase chain reaction and na $=$ not applicable
} 
conditions: $95^{\circ} \mathrm{C}$ for $10 \mathrm{~min}$ and 40 cycles at $95^{\circ} \mathrm{C}$ for $15 \mathrm{~s}$ and $60^{\circ} \mathrm{C}$ for $1 \mathrm{~min}$. All qPCR runs contained negative controls with no cDNA template. Specificity of the PCR amplification was checked using a heat dissociation protocol (from 60 to $95^{\circ} \mathrm{C}$ ) after the final cycle of the PCR. The similar efficiency of the primer sets was checked by performing qPCR on several dilutions of first strands. Results were standardized to the housekeeping PrEFlal (accession number HM219554) gene expression levels which displayed a low cycle threshold $\left(\mathrm{C}_{\mathrm{t}}\right)$ variation (standard deviation $=0.55 \mathrm{C}_{\mathrm{t}}$ ) for all samples and experimental conditions.

\section{Isolation of the PrSus1 promoter region.}

The 5' flanking sequence of PrSus1 was isolated by a PCRbased genome-walking procedure using the Universal GenomeWalker kit (Clontech, Saint-Quentin-en-Yvelines, France,). Genomic DNA was extracted from a flowering shoot (FS.V) using the DNeasy plant mini kit (Qiagen, Courtaboeuf, France) according to the manufacturer's instructions. Two non-overlapping gene-specific primers were designed based on the PrSusl cDNA sequence (Table 1). Primary PCR amplification was conducted using the PrSUS1-GenWalk1 and an adaptor primer 1. Cycling conditions consisted of an initial denaturation for 2 min at $94^{\circ} \mathrm{C}$; followed by 7 cycles of $25 \mathrm{~s}$ at $94^{\circ} \mathrm{C}, 50 \mathrm{~s}$ at $68^{\circ} \mathrm{C}$, and $3 \mathrm{~min}$ at $72^{\circ} \mathrm{C}$; then followed by 32 cycles of $25 \mathrm{~s}$ at $94^{\circ} \mathrm{C}, 50 \mathrm{~s}$ at $62^{\circ} \mathrm{C}$, and $3 \mathrm{~min}$ at $72^{\circ} \mathrm{C}$; with a final 10 -min extension at $72^{\circ} \mathrm{C}$. The secondary PCR amplification was performed with the PrSUS1-GenWalk2 and a nested adapter primer 2. Cycling conditions consisted of an initial denaturation for $2 \mathrm{~min}$ at $94^{\circ} \mathrm{C}$; followed by 5 cycles of $25 \mathrm{~s}$ at $94^{\circ} \mathrm{C}$, $50 \mathrm{~s}$ at $65^{\circ} \mathrm{C}$, and $3 \mathrm{~min}$ at $72^{\circ} \mathrm{C}$; then followed by 20 cycles of $25 \mathrm{~s}$ at $94^{\circ} \mathrm{C}, 50 \mathrm{~s}$ at $58^{\circ} \mathrm{C}$, and $3 \mathrm{~min}$ at $72^{\circ} \mathrm{C}$; with a final 10 min extension at $72^{\circ} \mathrm{C}$. PCR products obtained from the secondary PCR amplification were cloned and sequenced as described above.

\section{Sequence analysis.}

Bioinformatics analyses were performed using Vector NTI 9.1.0 software (Life Technologies Corporation). Sequence homologies were verified against GenBank databases using BLAST programs. Promoter motif searches were carried out using the PLACE software (Higo et al. 1999). Phylogenetic analyses were conducted in MEGA4 software (Tamura and Akutsu 2007). Amino acid sequences were aligned with Clustal W.

\section{Statistical analysis.}

An analysis of variance was performed on the results from qPCR analyses with the development stage or treatment as the tested factor using SigmaPlot version 10.0. Means of three independent RNA isolations were tested at $P<0.05$ (SNK test).

\section{ACKNOWLEDGMENTS}

We thank D. Bozec and J. Schmidt for their help with the plant cultures; B. Bouchet (Biopolymers-Interaction-Structural Biology facility, INRA Centre of Angers-Nantes, France) for the microscopy analyses; and H. A. Ross (Scottish Crop Research Institute, Invergowrie, Dundee, U. K.), who kindly provided the antibodies raised against faba bean SUS. This work was supported financially by a Ph.D. fellowship (to T. Péron) and funds from the French Ministry of Education and Research.

\section{LITERATURE CITED}

Abbes, Z., Kharrat, M., Delavault, P., Chaibi, W., and Simier, P. 2009. Nitrogen and carbon relationships between the parasitic weed Orobanche foetida and susceptible and tolerant faba bean lines. Plant Physiol. Biochem. 47:153-159.
Aber, M., and Sallé, G. 1983. Graine et procaulôme d'Orobanche crenata Forsk: Étude histocytologique et cytochimique. Can. J. Bot. 61:33023313.

Aber, M., Fer, A., and Sallé, G. 1983. Etude du transfert des substances organiques de l'hôte (Vicia faba) vers le parasite (Orobanche crenata Forsk.). Z. Pflanzenphysiol. 112:297-308.

Albrecht, G., and Mustroph, A. 2003. Localization of sucrose synthase in wheat roots: Increased in situ activity of sucrose synthase correlates with cell wall thickening by cellulose deposition under hypoxia. Planta 217:252-260.

Aly, R., Cholakh, H., Joel, D. M., Leibman, D., Steinitz, B., Zelcer, A., Naglis, A., Yarden, O., and Gal-On, A. 2009. Gene silencing of mannose 6-phosphate reductase in the parasitic weed Orobanche aegyptiaca through the production of homologous dsRNA sequences in the host plant. Plant Biotechnol. J. 7:487-498.

Amor, Y., Haigler, C. H., Johnson, S., Wainscott, M., and Delmer, D. P. 1995. A membrane-associated form of sucrose synthase and its potential role in synthesis of cellulose and callose in plants. Proc. Natl. Acad. Sci. U.S.A. 92:9353-9357.

Bar-Nun, N., Sachs, T., and Mayer, A. M. 2008. A role for IAA in the infection of Arabidopsis thaliana by Orobanche aegyptiaca. Ann. Bot. 101:261-265.

Baroja-Fernández, E., Muñoz, F. J., Montero, M., Etxeberria, E., Sesma, M. T., Ovecka, M., Bahaji, A., Ezquer, I., Li, J., Prat, S., and PozuetaRomero, J. 2009. Enhancing sucrose synthase activity in transgenic potato (Solanum tuberosum L.) tubers results in increased levels of starch, ADPglucose and UDPglucose and total yield. Plant Cell Physiol. 50:1651-1662.

Baud, S., Vaultier, M. N., and Rochat, C. 2004. Structure and expression profile of the sucrose synthase multigene family in Arabidopsis. J. Exp. Bot. 55:397-409.

Baumann, K., De Paolis, A., Costantino, P., and Gualberti, G. 1999. The DNA binding site of the Dof protein NtBBF1 is essential for tissue-specific and auxin-regulated expression of the rolB oncogene in plants. Plant Cell 11:323-334.

Bieniawska, Z., Paul Barratt, D. H., Garlick, A. P., Thole, V., Kruger, N. J., Martin, C., Zrenner, R., and Smith, A. M. 2007. Analysis of the sucrose synthase gene family in Arabidopsis. Plant J. 49:810-828.

Bologa, K. L., Fernie, A. R., Leisse, A., Loureiro, M. E., and Geigenberger, P. 2003. A bypass of sucrose synthase leads to low internal oxygen and impaired metabolic performance in growing potato tubers. Plant Physiol. 132:2058-2072.

Brewer, P. B., Dun, E. A., Ferguson, B. J., Rameau, C., and Beveridge, C. A. 2009. Strigolactone acts downstream of auxin to regulate bud outgrowth in pea and Arabidopsis. Plant Physiol. 150:482-493.

Buckeridge, M. S., Vergara, C. E., and Carpita, N. C. 1999. The mechanism of synthesis of a mixed-linkage $(1 \rightarrow 3),(1 \rightarrow 4) \beta$-D-glucan in maize. Evidence for multiple sites of glucosyl transfer in the synthase complex. Plant Physiol. 120:1105-1116.

Chourey, P. S., and Taliercio, E. W. 1994. Epistatic interaction and functional compensation between the two tissue- and cell-specific sucrose synthase genes in maize. Proc. Natl. Acad. Sci. U.S.A. 91:7917-7921.

Coleman, H. D., Yan, J., and Mansfield, S. D. 2009. Sucrose synthase affects carbon partitioning to increase cellulose production and altered cell wall ultrastructure. Proc. Natl. Acad. Sci. U.S.A. 106:1311813123.

Davis, C. C., and Wurdack, K. J. 2004. Host-to-parasite gene transfer in flowering plants: Phylogenetic evidence from Malpighiales. Science 305:676-678.

Delavault, P., Simier, P., Thoiron, S., Véronési, C., Fer, A., and Thalouarn, P. 2002. Isolation of mannose 6-phosphate reductase cDNA, changes in enzyme activity and mannitol content in broomrape (Orobanche ramosa) parasitic on tomato roots. Physiol. Plant. 115:48-55.

Delmer, D. P., and Amor, Y. 1995. Cellulose biosynthesis. Plant Cell 7:987-1000.

Draie, R., Péron, T., Pouvreau, J-B., Véronési, C., Jégou, S., Delavault, P., Thoiron, S., and Simier, P. 2011. Invertases involved in the development of the parasitic plant Phelipanche ramosa: Characterization of the dominant soluble acid isoform, PrSAI1. Mol. Plant Pathol. 12:638-652.

Duncan, K. A., Hardin, S. C., and Huber, S. C. 2006. The three maize sucrose synthase isoforms differ in distribution, localization, and phosphorylation. Plant Cell Physiol. 47:959-971.

Ehness, R., and Roitsch, T. 1997. Co-ordinated induction of mRNAs for extracellular invertase and a glucose transporter in Chenopodium rubrum by cytokinins. Plant J. 11:539-548.

Etxeberria, E., and Gonzalez, P. 2003. Evidence for a tonoplast-associated form of sucrose synthase and its potential involvement in sucrose mobilization from the vacuole. J. Exp. Bot. 54:1407-1414.

Fuglevand, G., Phillips, W., Mozzanega, P., Corley, S., Chengappa, S., and 
Shields, R. 1998. Mapping of tomato genes associated with sugar metabolism. Tomato Genet. Co-op Rep. 48:22-23.

Gardiner, J. C., Taylor, N. G., and Turner, S. R. 2003. Control of cellulose synthase complex localization in developing xylem. Plant Cell 15:17401748.

Geromel, C., Ferreira, L. P., Guerreiro, S. M., Cavalari, A. A., Pot, D., Pereira, L. F., Leroy, T., Vieira, L. G., Mazzafera, P., and Marraccini, P. 2006. Biochemical and genomic analysis of sucrose metabolism during coffee (Coffea arabica) fruit development. J. Exp. Bot. 57:32433258 .

Goda, H., Sawa, S., Asami, T., Fujioka, S., Shimada, Y., and Yoshida, S 2004. Comprehensive comparison of auxin-regulated and brassinosteroid-regulated genes in Arabidopsis. Plant Physiol. 134:15551573.

Gomez-Roldan, V., Fermas, S., Brewer, P. B., Puech-Pages, V., Dun, E. A., Pillot, J. P., Letisse, F., Matusova, R., Danoun, S., Portais, J. C., Bouwmeester, H., Becard, G., Beveridge, C. A., Rameau, C., and Rochange, S. F. 2008. Strigolactone inhibition of shoot branching. Nature 455:189-194.

Grierson, C., Du, J. S., de Torres Zabala, M., Beggs, K., Smith, C., Holdsworth, M., and Bevan, M. 1994. Separate cis sequences and trans factors direct metabolic and developmental regulation of a potato tuber storage protein gene. Plant J. 5:815-826.

Harada, T., Satoh, S., Yoshioka, T., and Ishizawa, K. 2005. Expression of sucrose synthase genes involved in enhanced elongation of pondweed (Potamogeton distinctus) turions under anoxia. Ann. Bot. 96:683-692.

Harb, A. M., Hameed, K. M., and Shibli, R. A. 2004. Effect of triiodobenzoic acid on broomrape (Orobanche ramosa) infection and development in tomato plants. Plant Pathol. J. 20:81-84.

Hayward, A., Stirnberg, P., Beveridge, C., and Leyser, O. 2009. Interactions between auxin and strigolactone in shoot branching control. Plant Physiol. 151:400-412.

Hibberd, J. M., and Jeschke, W. D. 2001. Solute flux into parasitic plants. J. Exp. Bot. 52:2043-2049.

Higo, K., Ugawa, Y., Iwamoto, M., and Korenaga, T. 1999. Plant cis-acting regulatory DNA elements (PLACE) database: 1999. Nucleic Acids Res. 27:297-300.

Johnson, A. W., Rosebery, G., and Parker, C. 1976. A novel approach to Striga and Orobanche control using synthetic germination stimulants. Weed Res. 16:223-227.

Johnson, X., Brcich, T., Dun, E. A., Goussot, M., Haurogne, K., Beveridge, C. A., and Rameau, C. 2006. Branching genes are conserved across species. Genes controlling a novel signal in pea are coregulated by other long-distance signals. Plant Physiol. 142:1014-1026.

Klinedinst, S., Pascuzzi, P., Redman, J., Desai, M., and Arias, J. 2000. A xenobiotic-stress-activated transcription factor and its cognate target genes are preferentially expressed in root tip meristems. Plant Mol. Biol. 42:679-688.

Koch, K. 2004. Sucrose metabolism: Regulatory mechanisms and pivotal roles in sugar sensing and plant development. Curr. Opin. Plant Biol. 7:235-246.

Koch, K. E. 1996. Carbohydrate-modulated gene expression in plants. Annu. Rev. Plant Physiol. Plant Mol. Biol. 47:509-540.

Koch, K. E., Nolte, K. D., Duke, E. R., McCarty, D. R., and Avigne, W. T. 1992. Sugar levels modulate differential expression of maize sucrose synthase genes. Plant Cell 4:59-69.

Komatsu, A., Moriguchi, T., Koyama, K., Omura, M., and Akihama, T. 2002. Analysis of sucrose synthase genes in citrus suggests different roles and phylogenetic relationships. J. Exp. Bot. 53:61-71.

Labrousse, P., Arnaud, M-C., Serieys, H., Berville, A., and Thalouarn, P. 2001. Several mechanisms are involved in resistance of Helianthus to Orobanche cumana Wallr. Ann. Bot. 88:859-868.

Lejeune, A., Constant, S., Delavault, P., Simier, P., Thalouarn, P., and Thoiron, S. 2006. Involvement of a putative Lycopersicon esculentum wall-associated kinase in the early steps of tomato-Orobanche ramosa interaction. Physiol. Mol. Plant Pathol. 69:3-12.

Martin, T., Frommer, W. B., Salanoubat, M., and Willmitzer, L. 1993. Expression of an Arabidopsis sucrose synthase gene indicates a role in metabolization of sucrose both during phloem loading and in sink organs. Plant J. 4:367-377.

Miyawaki, K., Tarkowski, P., Matsumoto-Kitano, M., Kato, T., Sato, S., Tarkowska, D., Tabata, S., Sandberg, G., and Kakimoto, T. 2006. Roles of Arabidopsis ATP/ADP isopentenyltransferases and tRNA isopentenyltransferases in cytokinin biosynthesis. Proc. Natl. Acad. Sci. U.S.A. 103:16598-16603

Ohashi-Ito, K., and Fukuda, H. 2010. Transcriptional regulation of vascular cell fates. Curr. Opin. Plant Biol. 13:670-676.

Parker, C. 2009. Observations on the current status of Orobanche and Striga problems worldwide. Pest Manage. Sci. 65:453-459.

Pérez-de-Luque, A., Fondevilla, S., Perez-Vich, B., Aly, R., Thoiron, S.,
Delgrange, S., Simier, P., and Delavault, P. 2009. Understanding broomrape-host plant interaction and developing resistance. Weed Res. 49:822.

Persia, D., Cai, G., Del Casino, C., Faleri, C., Willemse, M. T., and Cresti, M. 2008. Sucrose synthase is associated with the cell wall of tobacco pollen tubes. Plant Physiol. 147:1603-1618.

Pien, S., Wyrzykowska, J., and Fleming, A. J. 2001. Novel marker genes for early leaf development indicate spatial regulation of carbohydrate metabolism within the apical meristem. Plant J. 25:663-674.

Ricard, B., Toai, T. V., Chourey, P., and Saglio, P. 1998. Evidence for the critical role of sucrose synthase for anoxic tolerance of maize roots using a double mutant. Plant Physiol. 116:1323-1331.

Rispail, N., Dita, M. A., Gonzalez-Verdejo, C., Pérez-de-Luque, A., Castillejo, M. A., Prats, E., Roman, B., Jorrin, J., and Rubiales, D. 2007. Plant resistance to parasitic plants: Molecular approaches to an old foe. New Phytol. 173:703-712.

Rolletschek, H., Borisjuk, L., Koschorreck, M., Wobus, U., and Weber, H. 2002. Legume embryos develop in a hypoxic environment. J. Exp. Bot. 53:1099-1107.

Ross, H. A., and Davies, H. V. 1992. Purification and characterization of sucrose synthase from the cotyledons of Vicia faba L. Plant Physiol. 100:1008-1013.

Ruan, Y. 2007. Rapid cell expansion and cellulose synthesis regulated by plasmodesmata and sugar: Insights from the single-celled cotton fibre. Funct. Plant Biol. 34:1-10.

Sachs, T. 1981. The control of patterned differentiation of vascular tissues. Adv. Bot. Res. 9:151-262.

Sachs, T. 1991. Pattern Formation in Plant Tissues. Cambridge University Press, Cambridge.

Salnikov, V. V., Grimson, M. J., Delmer, D. P., and Haigler, C. H. 2001. Sucrose synthase localizes to cellulose synthesis sites in tracheary elements. Phytochemistry 57:823-833.

Salnikov, V. V., Grimson, M. J., Seagull, R. W., and Haigler, C. H. 2003. Localization of sucrose synthase and callose in freeze-substituted secondary-wall-stage cotton fibers. Protoplasma 221:175-184.

Shimizu-Sato, S., Tanaka, M., and Mori, H. 2009. Auxin-cytokinin interactions in the control of shoot branching. Plant Mol. Biol. 69:429435.

Slavov, S., van Onckelen, H., Batchvarova, R., Atanassov, A., and Prinsen, E. 2004. IAA production during germination of Orobanche spp. seeds. J. Plant Physiol. 161:847-853.

Sokolova, S. V., Balakshina, N. O., and Krasavina, M. S. 2002. Activation of soluble acid invertase accompanies the cytokinin-induced sourcesink leaf transition. Russ. J. Plant Physiol. 49:86-91.

Sturm, A., and Tang, G. Q. 1999. The sucrose-cleaving enzymes of plants are crucial for development, growth and carbon partitioning. Trends Plant Sci. 4:401-407.

Subbaiah, C. C., and Sachs, M. M. 2001. Altered patterns of sucrose synthase phosphorylation and localization precede callose induction and root tip death in anoxic maize seedlings. Plant Physiol.125:585-594.

Subbaiah, C. C., Palaniappan, A., Duncan, K., Rhoads, D. M., Huber, S. C., and Sachs, M. M. 2006. Mitochondrial localization and putative signaling function of sucrose synthase in maize. J. Biol. Chem. 281:15625-15635.

Tamura, T., and Akutsu, T. 2007. Subcellular location prediction of proteins using support vector machines with alignment of block sequences utilizing amino acid composition. BMC Bioinf. 8:466.

Tanaka, M., Takei, K., Kojima, M., Sakakibara, H., and Mori, H. 2006. Auxin controls local cytokinin biosynthesis in the nodal stem in apical dominance. Plant J. 45:1028-1036.

Tomilov, A. A., Tomilova, N. B., Wroblewski, T., Michelmore, R., and Yoder, J. I. 2008. Trans-specific gene silencing between host and parasitic plants. Plant J. 56:389-397.

Umehara, M., Hanada, A., Yoshida, S., Akiyama, K., Arite, T., TakedaKamiya, N., Magome, H., Kamiya, Y., Shirasu, K., Yoneyama, K., Kyozuka, J., and Yamaguchi, S. 2008. Inhibition of shoot branching by new terpenoid plant hormones. Nature 455:195-200.

van Dongen, J. T., Schurr, U., Pfister, M., and Geigenberger, P. 2003. Phloem metabolism and function have to cope with low internal oxygen. Plant Physiol. 131:1529-1543.

Westwood, J. H., Roney, J. K., Khatibi, P. A., and Stromberg, V. K. 2009. RNA translocation between parasitic plants and their hosts. Pest Manage. Sci. 65:533-539.

Winter, H., and Huber, S. C. 2000. Regulation of sucrose metabolism in higher plants: Localization and regulation of activity of key enzymes. Crit. Rev. Biochem. Mol. Biol. 35:253-289.

Winter, H., Huber, J. L., and Huber, S. C. 1998. Identification of sucrose synthase as an actin-binding protein. FEBS (Fed. Eur. Biochem. Soc.) Lett. 430:205-208.

Winzer-Serhan, U. H., Broide, R. S., Chen, Y., and Leslie, F. M. 1999. 
Highly sensitive radioactive in situ hybridization using full length hydrolyzed riboprobes to detect alpha 2 adrenoceptor subtype mRNAs in adult and developing rat brain. Brain Res. Protoc. 3:229-241.

Wu, A. M., Hu, J. S., and Liu, J. Y. 2009. Functional analysis of a cotton cellulose synthase A4 gene promoter in transgenic tobacco plants. Plant Cell Rep. 28:1539-1548.

Yoneyama, K., Xie, X., Yoneyama, K., and Takeuchi, Y. 2009. Strigolactones: Structures and biological activities. Pest Manage. Sci. 65:467470.

Yoshida, S., Iwamoto, K., Demura, T., and Fukuda, H. 2009. Comprehensive analysis of the regulatory roles of auxin in early transdifferenciation into xylem cells. Plant Mol. Biol. 70:457-469.
Zhou, W. J., Yoneyama, K., Takeuchi, Y., Iso, S., Rungmekarat, S., Chae, S. H., Sato, D., Joel, D. M. 2004. In vitro infection of host roots by differentiated calli of the parasitic plant Orobanche. J. Exp. Bot. 55:899907.

AUTHOR-RECOMMENDED INTERNET RESOURCES

Parasitic Plant Connection website: www.parasiticplants.siu.edu/Orobanchaceae/Orobanche.Gallery.html NCBI BLAST programs: www.ncbi.nlm.nih.gov/blast

NIAS DNA Bank PLACE software: www.dna.affrc.go.jp 